and nobody is quite sure how they do it. Keeton (J. comp. Physiol., 83, 1; 1973) suggests that a valuable clue to this mystery may be supplied by exploiting a curious fact about pigeon homing: when released from a site well away from their home loft, pigeons depart non-randomly, but the mean vanishing bearing almost never coincides with the direction of their home. Instead, the birds set off in a direction which consistently deviates from home and correct themselves later on in the flight. What is more, this initial deviation is often characteristic of a given release site. If these 'release-site biases' are due to some local distortion of geophysical cues that the birds are using, then finding out about the nature of this distortion may help one to understand what navigational system the birds are using.

Keeton investigated a particular release site 89 miles NNE from his lofts in Ithaca, NY, from which his pigeons consistently fly off on a bearing about $60^{\circ}$ to the right of the home bearing. By releasing numbers of birds (singly, so they did not influence one another) he found that a similar directional bias was shown by the pigeons whether or not the Sun was visible and whether the birds were experienced homers or on their first flight ever away from the loft. The biasing factor at the release site does not, then, seem to be dependent on weather or on the experience of the birds. Pigeons from other lofts and bank swallows also deviated in the same clockwise direction.

Keeton also found that it is not some feature of the landscape which attracts or repels the pigeons. It is well known that keeping pigeons in an artificial lightdark regime which is ahead or behind that of the outside world will result in their vanishing bearings being shifted to left or right (the 'clock shifting' gives them a false idea of time and upsets their ability to use the Sun as a timecompensated compass). By clock shifting birds 4, 5 , or $6 \mathrm{~h}$ forwards, Keeton was able to make his birds set off more directly towards home. In other words, pigeons will fly directly homewards if their navigational system tells them that this is the direction to go. Keeton is at present trying to find out what it is about this release site that causes the navigational system to respond inappropriately, for he believes that his birds are not making an error, but are probably taking readings correctly from a distorted 'map'.

\section{COLLOID SCIENCE}

\section{Magnetic Filiration}

from our Materials Science Correspondent

A GOOD criterion for judging whether a piece of research is suitable for summarising in News and Views is the difficulty found in choosing a heading for the possible story. This one is headed 'colloid science', but it might equally well have been 'applied physics', 'magnetism', 'fluid dynamics', 'filtration' or 'pollution abatement'. Interdisciplinarity is all the rage, and is common enough in teams: what is much rarer, and apt to get results, is the one-man interdisciplinary team.

J. H. P. Watson is one of these monanthropic teams. He has just outlined (J. appl. Phys., 44, 4209; 1973) the principles of a new method of filtration. $\mathrm{He}$ examines the behaviour of a suspension of small paramagnetic spheres in a liquid flowing at right angles to a ferromagnetic wire when a steady magnetic field is applied parallel to the direction of fluid flow. Briefly, the particles are attracted to the wire and will adhere to it if they pass within a critical distance which is itself a function of flow rate, wire diameter, particle diameter, ferromagnetic permeability and paramagnetic susceptibility. The most important parameter or figure of merit seems to be the ratio of the fluid velocity to a 'magnetic velocity', which unfortunately is nowhere defined or explained.

Watson goes on to consider the efficiency of a filter of crumpled wire in a field, in terms of the packing fraction and the above-mentioned figure of merit, both for streamline flow and for the less tractable case of turbulent flow. Such a filter, given a sufficiently strong field and fine particles, could be highly efficient, a kind of liquid-flow analogue to the electrostatic precipitators used for smoke. Watson considers the special case of sewage. Here it would be necessary to use paramagnetic powder, such as haematite, as "nuclei for activatedsludge flows", and then to extract the powder from the filtrate and recycle it. Watson claims that such a filter would be 100 times more efficient than a sand filter of the same area-perhaps a rather modest factor of improvement in view of the probable capital and process costs, but interesting nonetheless. $\mathrm{He}$ suggests that a superconducting magnet would be needed to attain a sufficiently high field (no field-strength is quoted anywhere), and that a 12 -foot diameter magnet/filter could process $2.5 \times 10^{7}$ gallons a day and serve a city of 0.5 million. The economics of this proposal would be intriguing in the extreme -it is hard to see whether it would be an environmentalist's Concorde or an ultra cost-effective vehicle for recycling haematite, liquid helium and water.

The particular application proposed may provoke a measure of scepticism and the theoretical treatment, as published, may raise a number of unanswered questions, but the filtration technique is one with most interesting potential, especially if the theory can be experimentally confirmed.

\section{PLATE TECTONICS}

\section{Subduction Reverses}

from our Geomagnetism Correspondent ONLY a few years ago, heat flow studies were often regarded as the poor relation of the geophysical family; the results were interesting but it was difficult to see what conclusions could be drawn from them. The most striking fact to have emerged in the early days of heat flow work was that the average continental and oceanic heat flows are approximately equal, and this was felt intuitively to be important even though its implications were far from clear. But even this unexpected discovery had little impact on the mainstream of geophysical thought, precisely because of the problem of interpretation. Today, how. ever, the situation is quite different. For one thing, Sclater and Francheteau (Geophys. J., 20, 509; 1970) have shown convincingly that the continental-oceanic equality is largely irrelevant because it fails to take account of variations in heat flow with age. But on the more positive side, heat flow data are now playing a much more significant part in the detailed interpretation and clarification of plate tectonic processes.

A good example of this is provided by new and old heat flow results from the western equatorial Pacific (Halunen and Von Herzen, J. geophys. Res., 78, 5195; 1973). The equatorial Pacific west of Hawaii is a large and complex area still very poorly understood in plate tectonic terms and for which geophysical data are still relatively sparse, although its extensive arc-trench system is generally believed to indicate a set of convergent plate boundaries. But in this general scheme of things, the Solomon Islands region is apparently anomalous. In much of the western equatorial Pacific the island arcs are associated with trenches and subduction zones produced by lithospheric spreading from the Pacific side; and on this basis the Solomon Islands, which stretch out in a roughly northwest-southwest direction, would be expected to have a trench on the northeast side. But this is not so; the trenches in this region lie on the continental side of the island arc system.

To help explain this apparent discrepancy, Halunen and Von Herzen have turned to good advantage the Earth's high thermal inertia, a phenomenon which is often regarded as more of a hindrance but which in this case enables recent changes in plate tectonic behaviour to be identified. Combined newly and previously obtained data show that immediately northeast of the Solomon Islands the heat flow is low at about $35 \mathrm{~mW} \mathrm{~m}^{-2}$ but increases to 'normal' (about $64 \mathrm{~mW} \mathrm{~m}^{-2}$ ) out in the Pacific to the north. To the southwest of the islands, on the other hand, heat flow is high at about $83 \mathrm{~mW} \mathrm{~m}^{-2}$, with two 